of animal consciousness probable. If they are correct, then the persistence of the cartesian legacy in the period after Darwin - the subject of the book's second half is all the more surprising. Perhaps their claim is overstated. Arguing from the case of one species seems mighty risky. And perhaps the significance of consciousness is magnified in human eyes so that we wrongly think it must be expected to exist in many other animal forms. The authors' preferred explanation points to the failure - for example, of the early comparative role for consciousness, a place in the causal network. To this they add the positivist-inspired doubts about the testability of ascriptions of conscious states, and some powerful reworking of Descartes' doubts about the capacities of animals for communication and reasoned action. The Radners confront these new and renovated problems with resolution and ingenuity. Their re-evaluations of three prominent examples of alleged mindlessness in animals are among the best things in the book which, overall, is well constructed and adroitly argued.

My chief criticism concerns what they haven't done, or haven't done thoroughly enough. Having argued that 'there is something it is like to be an animal' - to use Tom Nagel's illuminating phrase the next question is how we are to discover what it is like. Although they recognize the problem, the Radners don't take us very far along this road. In the matter of psychologists - to find an explanatory

whether it is better to be a dissatisfied human being or a satisfied pig, John Stuart Mill was confident that human beings know both sides of the question.

Although they must agree with Mill in principle, the Radners rightly observe that matters are not that simple. Because desires are integrated differently in a pig, they say, and because pigs have "desires of their own" (they don't say how they know this), the comparative judgement is problematic.

In another case involving attempts to communicate with primates, they observe, reasonably enough, that the question asked of the gorilla, Koko, "Where do gorillas go when they die?" is a human question. For Nim the chimpanzee, who had tested new teachers by aggressive displays, they suggest "Me boss you?" as a more appropriate reflection of Nim's world. Yet, it seems to me, they may be seriously underrating the difficulties of entering the porcine or simian worlds. It is within the human world that Nim's response is construed as aggressive. It seems rash to assume that the response bears that construction in the rather differently structured world of the chimpanzee. In problems such as these lie the fascination and challenge of the study of animal consciousness which, in a suitably sensitive and disengaged form, seems barely to have begun.

Alan Holland is in the Department of Philosophy, University of Lancaster, Lancaster LA1 4YT, UK.

\section{Out of chains}

\section{John Bell}

PCR Technology: Principles and Applications for DNA Amplification. Edited by Henry A. Erlich. Stockton, New York Macmillan, London: 1989. Pp.246. Pbk \$19.95, £15.95.

Compiling a book on a technique that is developing rapidly presents considerable difficulties. It is perhaps for this reason

\section{PCR and more besides}

'LONG-awaited' is the tag publishers on occasion apply to their books that appear months, even years, after they were first announced - and, it turns out, to indifferent public reaction.

That should not be the fate of the longawaited second edition of Molecular Cloning: A Laboratory Manual, even though molecular biologists are still waiting for it. First announced for publication by Cold Spring Harbor Laboratory Press in October 1988, the second edition will appear next month.

The reason for the delay is that the that almost three years have passed without a serious attempt being made to assemble a volume on the polymerase chain reaction (PCR). This technique, which permits the in vitro amplification of specific DNA sequences, is now one of the most powerful tools available to molecular biologists. New applications and adaptations have been appearing so quickly that even journals are having a difficult time keeping up.

No group is more suited to review the field than Henry Erlich and his colleagues at Cetus. It was from their laboratory that

decision was taken to include the developments of 1988 and early 1989. Principal amongst these is PCR technology, the subject of a new chapter. Overall, the material has been split into three volumes, and although the authors remain the same the second edition becomes Sambrook et al. rather than Maniatis et al.

Sambrook et al. will face much more competition than they did before (for some of the contenders see Nature 333, $309 ; 1988)$. But the work's biblical status and its remarkable price (\$97) will no doubt make it a compulsory purchase. TL the idea arose and was systematically and rapidly developed. In this book, the Cetus group and their co-authors are extremely successful in conveying both the theoretical and the applied aspects of PCR.

An initial section on basic methodology and its application provides a clear yet detailed chapter describing protocols and conditions for PCR and an excellent chapter on the polymerase enzyme obtained from Thermus aquaticus (Taq). Through its stability at high temperatures, Taq has permitted the technique to be automated and hence widely applied. Although Cetus has a substantial commercial interest in both the enzyme and a PCR thermal cycler, there is little direct promotion of their products - except perhaps for the criticism of water-cooled thermal cyclers because they waste water and are therefore ecologically unsound!

The second part of the book is devoted to evaluating applications. Modifying DNA, cloning new genes, detecting mutations, inverted PCR and numerous other variations on the basic technique are described. Not all of the modern adaptations are included -- anchor PCR, quantitation (and its problems) and CA repeat mapping are not discussed. But that was inevitable; not only are things moving so fast, but a comprehensive review of research applications would have made the book unmanageable.

The field where PCR is most likely to have its greatest impact is human genetics, and the contributors to the third section, "Medical Applications", are mostly drawn from this camp. As well as chapters on genetic diagnosis, HLA polymorphism and oncogenes, there are discussions of forensic applications and detection of infectious disease. These latter two chapters are likely to be of special importance in the future.

A notable feature of the book is its emphasis on practical aspects of the technique - every chapter is written by innovative scientists and is accompanied by detailed protocols. In particular, careful attention is paid to contamination. This failing of PCR is related to its greatest strength, because extreme sensitivity commonly leads to the spurious amplification of DNA contaminants. The problem is thoroughly addressed by the authors, and if their advice is taken it can clearly be contained.

This volume is long overdue. It lives up to all expectations, and will be valuable to both the neophyte and the experienced PCR scientist. The only recommendation I can add is that it should be purchased and read quickly, for if the field continues to move as quickly as it has the authors will be writing the next edition early in 1990 .

John Bell is in the Molecular Immunology Group, Institute of Molecular Medicine, John Radcliffe Hospital, Headington, Oxford OX3 9DU, UK. 